\title{
Review Article \\ Concept Maps for Teaching, Learning, and Assessment in Electronics
}

\author{
Valery Vodovozov and Zoja Raud \\ Tallinn University of Technology, Ehitajate Tee 5, 19086 Tallinn, Estonia \\ Correspondence should be addressed to Valery Vodovozov; valery.vodovozov@ttu.ee
}

Received 21 July 2014; Accepted 16 December 2014

Academic Editor: Lieven Verschaffel

Copyright ( 2015 V. Vodovozov and Z. Raud. This is an open access article distributed under the Creative Commons Attribution License, which permits unrestricted use, distribution, and reproduction in any medium, provided the original work is properly cited.

\begin{abstract}
The paper describes how to employ the concept mapping technology in engineering education in the field of Electronics. The overall knowledge domain ontology in the field is shown. It is underlined that the concept maps serve as a suitable tool to support instructors in promoting students' comprehension of the studying material and in improving their understanding of new concepts. Introduction of an original educational thesaurus is proposed. Such a thesaurus helps learners to see what they have acquired from the lessons. It supports them in making connections between new and prior concepts and reinforces knowledge integration by such a promotion. The developed concept maps are regarded as a valuable instrument of many assessment procedures. They represent learners' knowledge providing informative and reflective feedbacks tailored to learners' personal styles and requests.
\end{abstract}

\section{Introduction}

Currently, many universities seek better ways to enhance their educational technologies which, according to the UNESCO documents, should provide novel organisational arrangements for creation, application, and defining teaching, learning, and assessment processes and resources with their common integration. The main objectives are to arrange high-quality educational process to motivate students to learn both the skills directly related to their speciality and the additional knowledge domains valuable in the professional working environment.

Knowing what and how students learn is important for judging the appropriateness of learning objectives and deciding how to improve instruction. As in any discipline, in Electronics students start their training from the basic concepts of the discipline through an introductory course. In our case, it is Electronics and Semiconductor Engineering discipline. Next year they continue their study through Power Electronics. The preliminary discipline introduces simple concepts like semiconductors, electronic devices, amplifiers, filters, and digital components. In the major course, the students explore power converters, including their characteristics, interconnection, basic calculations, and design issues. Educators try to supply the graduates with knowledge about the general concepts of the field and to enhance their understanding of the ties between other topics for their future studies. However, both the learners and the instructors face many problems in these courses [1].

Teachers often expect learners to find for themselves connections between the concepts they learn in Electronics and the materials they study across other courses in their curriculum. In so doing, educators rely on the new educational technologies that enable trainee to access great amounts of studying volumes. Many supplies give the students additional data including the printed and the virtual ones. The printed resources cover tutorial aids, textbooks, lecture notes, labs, exercises, quizzes, exams, and so forth. In the virtual group the e-books, software, web manuals, and databases are represented along with learning portals, social networks, and webinars. The learners' and educators' exchange upon the partner agreements and international programmes also increases students' activity. In addition to the usual university resources, the learning tools of the partner institutions and enterprises are used along with the open Web resources which are now accessible for learning. Most of them were described deeply and explained in [2]. 
In addition, the educators are often disappointed if the learners have failed to tie expected nodes because they disregard the situation where wide knowledge proliferation often leads students to such a serious problem as an information overload [1]. During work without help, the students come across fragmentary and scrappy information, often resulting in disappointing and impossibility to make systematic and complete knowledge in the field.

It is enough problematic for learners to express a comprehensive map of Electrical Engineering, Physics, Electronics, Power Electronics, and similar domains because of the diversity of the concepts in the appropriate curricula. For many students perception of the practice and theory behind the studied topics and their interconnections is not easy. Many materials are inapplicable for labs and exercises. When learners find these courses difficult for understanding, it brings down their motivation in studying and success of learning. In [3], the similar reasons have been explained regarding some other engineering disciplines. In addition, it is a problem for the faculty to design the course content in a proper form at the required level.

Many studies focus on the approaches to increase understanding of the large volumes of information. Contemporary curricula management became inappropriate for both the teachers and the students who require regular enhancing of their professional level. To overcome such limitations, the new methods were developed in the global teaching practice. In particular, an effective "curriculum container system" has been proposed in [4]. Such a five-level composition including the curriculum, unit, task, episode, and element levels became enough complex for educators who needed to follow it along the full educational process. The educator's activity is restricted in this case by the curricula "aggregates"; hence any time when a teacher decides to modify the educational trajectory, the curriculum has to be changed. Another popular instrument to improve learning is a "conceptual graph" for knowledge representation [5]. An experience has shown that this method elaborates the storing technique that has more influences on the syllabi volume rather than on the structure of the curriculum.

The papers [6, 7] have observed the methods to affect the knowledge acquisition using such objects like headings, titles, overviews, previews, typographical cues, summaries, number signs, recall sentences, summary indicators, and indicators of importance. All kinds of such objects produce better information storing; nevertheless, memory for "unsignaled" data is often unaffected. Study of [6] has shown that proper arrangement of learning volume and context successfully increases the amount of knowledge that students can acquire as well as their overall comprehension. It has been proved in [1] that graphical representation of studying volume can reduce the information overload and students' disorientation.

Concept mapping represents one of the most powerful graphical tools for the knowledge acquisition [8,9]. Following [10-12], the concept maps support students in understanding the novel topics by mapping the links among new and previously studied domains.
Based on the concept mapping methodology, this paper aims to report an original study related to the enhancement and refining of a teaching strategy and technique of engineering education in Electronics. The first part of work focuses on the concept map employment in Electronics domain where the authors have developed the set of concept maps and associated graphical network resources. Next, the paper explains how to define the required concepts using multiple knowledge resources, to design the requested concept maps, and to arrange the learning objects referring to these concepts. In the further sections it is shown how the concept maps assist learners in understanding the Electronics knowledge domain and in the concept of cross-linking. The proposed concept maps are employed as an instrument for improving understanding of learned areas both before and after the lessons. Finally, the paper demonstrates how a particular concept status can affect different learning goals thus giving the students some adaptive guidance for the course appreciation.

\section{Ontology of Knowledge Domains}

In the same way as with other engineering disciplines, Electronics can be discussed as a knowledge domain, which collects some finite volume of concepts and the links existing among these concepts. A representation of such a collection suitable for knowledge reuse and sharing is known as ontology [13]. Commonly instructors apply ontology made by domain experts in the corresponding field of science to prepare their course syllabus in a way that mitigates knowledge overload and information disorientation. Besides, teachers also use ontology to design their tutorial aids and to prepare some learning tools to guide their students [14].

To display ontologies and to transfer them from instructors to trainees, a specific system is required which would provide some abstract, formalized, and simplified imaging of the studied phenomena and their interactions. Usually, three types of such systems are used, namely, mathematical models, descriptive models, and graphical ones [15].

Graphical systems employ symbols and diagrams that illustrate relationships of the former two model types. The concept maps have been defined in $[16,17]$ as graphical representations of knowledge comprised of concepts with their relationships. Graphical representation of the concept hierarchy and connection has its origin in constructivism, which explains how to use prior knowledge as a framework for learning the new knowledge. From the constructivist viewpoint, a learner acquires the new knowledge through an integrating of the new concepts with the existing ones [18]. This stresses the importance of prior knowledge in learning the novel concepts. In $[19,20]$ concept mapping was represented as a first stage in ontology development. Following [21], it may also be used flexibly to display a knowledge topology for meaningful learning together with the educational thesauri.

An interest in concept maps was originated from their interconnection with both the memory theory and the educational science [22]. A prominent statement of the semantic 
memory theory refers to associative knowledge networks. Its major premise is that knowledge is memorized as a network of the interconnecting concepts. The more close the knowledge representation is tied, the more likely a learner will recall the data at the appropriate moment. In this way, a network represents an integration of multiple concepts. This theoretical base has resulted in practical approaches that employ concept maps as the semantic networks.

One of the well-known concept map environments is CMAPTools [17]. This software originated from the Institute for Human and Machine Cognition (IHMC) which empowers students and teachers, collaboratively or individually, to display their knowledge and to share them among peers and colleagues. IHMC has established the set of public servers available for free for educational use that support the sharing of knowledge. The client-server architecture of CMAPTools maintains the knowledge sharing through the concept map servers and enables concept maps to be connected to related domains and to other types of media, such as videos, images, and homepages. Also, CMAP is a tool which facilitates publishing through the Web with automatically converting the concept maps to HTML formats suitable for browsing Internet [23]. Today, CMAPTools are broadly applicable in engineering activity thanks to their focus on procedural and product interfaces. Common concept map patterns are very indicative for cognitive status. Along with CMAPTools, some other concept-based graphic tools exist but they have another focus on the conceptual relationships, object identities, and their functional roles.

To facilitate educational problem resolving, concept maps were introduced to a variety of educational applications, including learning and instruction, curriculum design, and assessment in mechanics, chemistry, informational technology, and so forth [24]. They provide a useful environment for beginners, instructors, adaptive course developers, and learners in understanding the whole picture of the studied knowledge area. Researchers apply the concept maps in communication needed for the course design and instructional activity construction.

The role of the concept mapping is currently shifted from individual learners to collaborative learning promoting [25]. The former aims to support the personal learning, thereby helping the instructor or student to find errors in knowledge acquisition or to merge acquired and old concepts. On the other hand, the latter improves contacts between learners and teachers and indeed the problem understanding. Some studies, for example [26], have found that collaborative concept mapping enhances students' interaction and helps them in learning the particular parts of curricula. Many methods were found to generate new knowledge and to share information. The collaborative techniques were implemented to arrange different activities [27], methods of interaction (synchronous, asynchronous, or both), management [28], and common work. Remote users learned how to collaborate synchronously and asynchronously in the map design, commenting, and peer reviewing. The students have obtained a technique for sharing their maps and the feedback arrangement.

\section{Educational Thesaurus}

An effective descriptive model in the form of educational thesauri (ET) has been developed by the authors of this paper as the first step of the Electronics ontology design [2]. In contrast to other well-known thesauri, ET was intended primarily for educational purposes. It has been taken into account that every discipline studies the concepts in a specific context and gives them distinctive meanings that deviate from the meaning of the same words in other contexts and in everyday language. A properly organised course ET is described by a direct acyclic graph whereas a speciality thesaurus is represented by the forest of such graphs. Based on this target, the ET topology estimation and the definition were given in [29].

To build ET, the key concepts in Electronics were first chosen as candidates to be included to ET [30]. Such concepts proposed by different authors are not always consistent as they often describe the same concepts using similar terms but not exactly the same ones. Therefore, these terms were primarily classified by instructors into appropriate groups to reduce their total number. Next our purpose was to summarize the large datasets by removing any redundancy in the data for finding the key concepts. At last, an evaluation of "relation strength" was decided. In the simplest case, a linear topology with no loops and minimal concept linking was proposed. However, many concepts have complex relationship whereas some of them have no interconnections with other concepts within the domain and such decoupling was minimized.

The ET created to store these grouped terms has become a suitable tool from this viewpoint [31]. Every ET entry represents an article explaining a separate concept, including its term and definition. A concept whose meaning is described by a particular entry was called a defined concept whereas earlier introduced entries used to explain a defined concept were called parents. Ten lines below represent a very short fragment of an educational thesaurus for the Power Electronics course [32] where the following concepts are defined:

(1) "power electronic converter (PEC)": electronic converter that converts energy in a power electronic system,

(2) "dc/dc converter": "PEC" converting $d c$ to $d c$ of another level,

(3) "load": object connected to the "PEC" output,

(4) "supply": power line feeding the "PEC,"

(5) "boosting": generation of the "load" voltage whose level is higher than that of the "supply" voltage,

(6) "booster": "PEC" with "boosting" possibilities,

(7) "boost converter": "booster,"

(8) "switching dc converter": "dc/dc converter" built on a switching principle of operation,

(9) "buck converter": "switching dc converter" the output voltage of which is less than the input voltage, 
TABle 1: Fragment of the concept table in Power Electronics.

\begin{tabular}{llll}
\hline$i$ & Term & Parent 1 & Parent 2 \\
\hline 1 & PEC & & \\
2 & Load & PEC & \\
3 & Supply & PEC & Supply \\
4 & Boosting & Load & Boosting \\
5 & Booster & PEC & \\
6 & Boost converter & Booster & \\
7 & dc/dc converter & PEC & \\
8 & $\begin{array}{l}\text { Switching dc } \\
\text { converter }\end{array}$ & dc/dc converter & \\
9 & Buck converter & Switching dc & \\
& Buck-boost & converter & Buck converter \\
10 & converter & & \\
\hline
\end{tabular}

(10) "buck-boost converter": "buck converter" combined with a "boost converter."

Here, the concept terms are given between quotation marks and an italic font is used for the terms incoming from prior disciplines, such as Electronics and Electrical Engineering. The defined concept terms occupy the left side of each line whereas the definitions are to the right. In Table 1, a fragment of the ordered concept table is presented.

These ranked thesauri now accompany many electronic documents of the courses related to learning Electronics in Tallinn University of Technology. With the help of interactive hyperlinks, an educational thesaurus clarifies and explains the concepts through other learning materials including lectures and practical aids. This interactive hierarchically structured dictionary explains currently about 1000 concepts in the Power Electronics. Every ET entry has a semantic (meaningful) connection with the earlier given definitions. An alphabetically ordered thesaurus index is arranged as the database table. Also, a thematic index exists which guides the learner throughout the discipline, from the root concept to the leaves of the knowledge tree.

\section{Concept Maps as a Teacher Tool}

Following [33], the above approach applied to teaching Electronics should represent accurate information about the knowledge domains studied. As any map is a graphical representation of a more or less ET fragment, during the map development we selected the set of concepts and the linking words to arrange the basic propositions in the field. These concepts were accomplished in a proper topology at which more general concepts appear higher in the map, and more specific concepts occupy lower levels. Concepts within the same level of generalization were located in the same topological levels. Therefore, the outcome of our concept mapping is comprised of concepts, relationships, and a topology.
In [1], the procedure of knowledge transfer has been shared between four main steps:

(i) information retrieval,

(ii) concept extraction,

(iii) search for the key concepts,

(iv) evaluation of "relation strength."

According to this organisation, before constructing a concept map for a domain, every teacher in our team has distinguished between content covered through lecturing and content provided through labs, exercises, and other studies. Additionally, such informational resources as textbooks, scientific and popular books, and websites supply the students with required data also. To arrange successful concept extraction, the instructors collected their terms in an educational thesaurus where they summarised large datasets and removed data redundancy. During this process, the evaluation of concept "relation strength" has been decided. In the simplest case, a linear map topology without loops and with minimal concept linking could be proposed. However, so far as many concepts have complex interconnection and, on the contrary, some concepts have no links with other concepts, the teachers minimized such decoupling using the peer-to-peer communication.

We have found that a focus question of the particular lesson should be interpreted by no more than 25 concepts. This demand affects concept mapping with minimal redundancy and minimal loss of information. Therefore, simplicity is the first important instructor's requirement. If a concept set is too large, several concept maps can be used. In the same way, summaries were created for a chapter and for a part of the studied domain.

Concept maps of different instructors are subjective, because every concept map represents the author's individual knowledge and skills. In an educational context, a teacher wants to infer the student's understanding and perspective on a topic. The educator also wants that terminology used by the student would enable assessment of the outcomes, so the concept maps should be represented by different resources in the same way, that is, using the same words. This requirement affects concept mapping in two ways:

(i) the concepts and relations are to be extracted from a common basic ET,

(ii) the concept hierarchy has reflected the importance of the concepts in the particular domain.

Based on the above regulations, the major problem in the concept map design was to discriminate the most meaningful concepts from the less important ones. Thus, the first step taken by the instructors was to consider which concepts are most essential, those that the student should not obviate. The second step of a concept map creation was to join the concepts in a meaningful information structure. In this way, a specific network was designed consisting of concept nodes (points, vertices) and links (arcs, edges) which provides such relations among concepts as "is a," "related to," or "part of." Besides these two steps, another quality details have appealed the map 


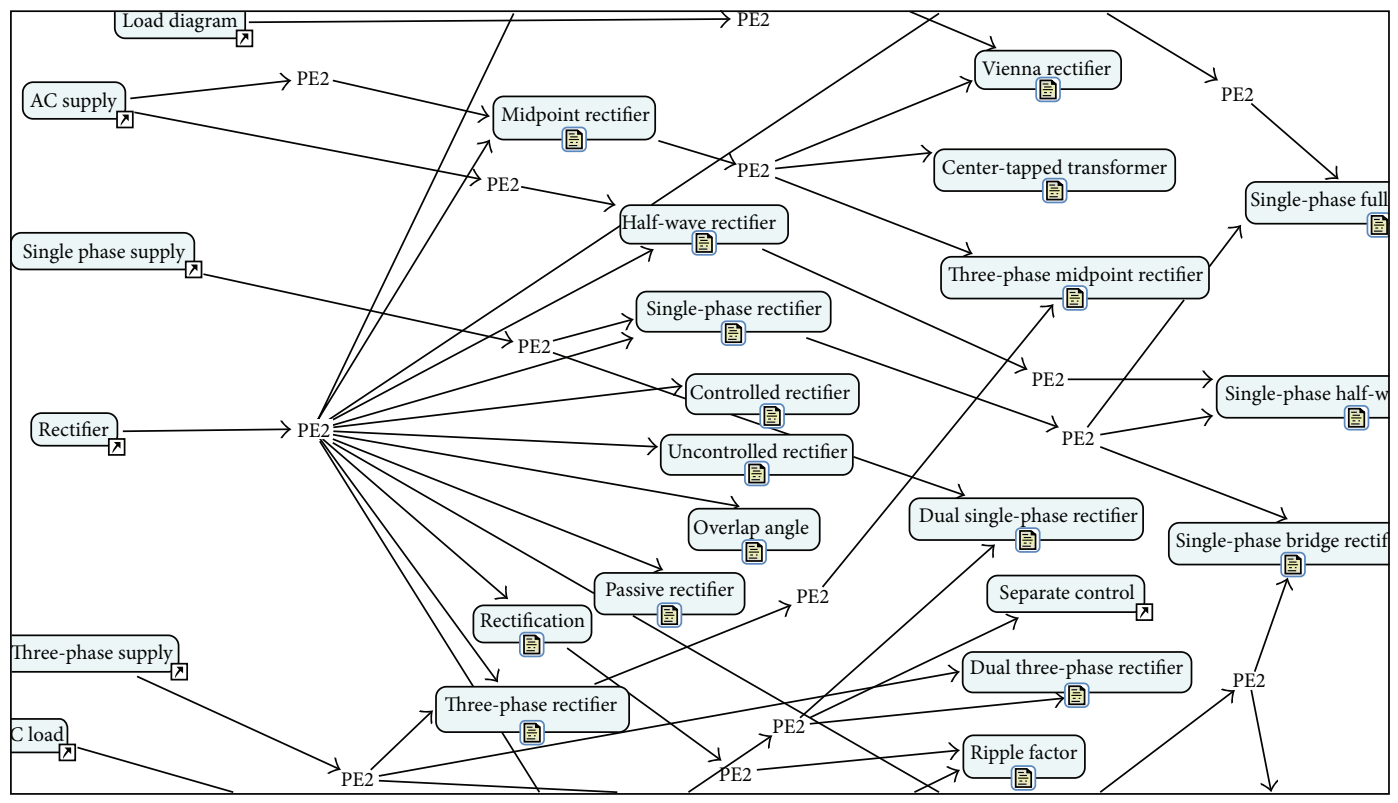

FIgURE 1: Fragment of concept map in Power Electronics.

designer's interest, such as segregating of the major concepts from the rest using different highlighting (colours, fonts, shapes, etc.), representative figures, and icons and connecting to external websites, applications, or the concept maps from other institutions. The maps developed also include crosslinks between concepts of different domains that show how one knowledge domain is related to another domain.

Figure 1 represents a fragment of the thesaurus built for Power Electronics in the CMAPTools environment. All the maps developed include the nodes with the key concepts enclosed in rounded rectangles. Each concept has the individual definition label. In the topology, the concepts are represented in a hierarchical fashion with the most general concepts at the left side and the less general concepts arranged hierarchically to the right. Concepts of the equal generalization level are located in the same topological level. The hierarchy of a particular subdomain is also defined on the context in which its information is being applied or considered. The cross-links are shown in the map as the named shortcuts. As a result, the outcome of the concept maps comprises concepts, relationships, and a topology.

The concept maps developed became a suitable tool supporting the teachers in promoting students' comprehension of the learning material and improving their understanding of new material.

\section{Concept Maps as a Student Tool}

The aim of concept mapping for learners is to interpret learners' personal understanding and their possibilities to draw individual examples against the existing theoretical and practical tasks. As the concept maps represent graphically some of ET fragments being a flexible tool to focus attention on important aspects of knowing, they help to explore what students are actually learning and how they do it.
Mapping process demonstrates what learners see as important concepts and how they relate these concepts. The results of mapping can have implications for clarifying the learning objectives, refining instructional strategies, identifying appropriate assessment tools, and understanding how the learning objectives are being realized by students.

Concept maps are commonly used for learning using one of the two following ways:

(i) students are asked to develop their own concept maps following a topic in the focus,

(ii) students are asked to analyze some preliminarily designed concept maps built by instructors or other learners.

Both approaches look to be effective tools in improvement of the learning outcomes. These maps engage in a process of reflection, collecting, and selecting appropriate knowledge. According to [34], the concept maps allow students

(i) to develop a flexible structure for self-directed learning,

(ii) to manage large amounts of information in the knowledge base which they build in the learning process,

(iii) to track personal progress in various areas and aspects,

(iv) to share their maps with others for feedback or evaluation,

(v) to facilitate setting up the personal learning goals.

When concept maps are designed in the classroom, we follow the recommendations of [35] and restrict usually the mapping time by 5 to 20 minutes. On the contrary, if mapping specifies their homework, learners will have 
a lot of information from numerous sources, such as books, Internet, and other digital media libraries. The contents of these sources can be useful to appreciate the course or to simplify knowledge understanding. Otherwise, it is not a trivial job for students to organize and identify the main thematic topics. Therefore, students force multiple learning objects and make notes in their concept maps to personalize learning, to increase skills, and to promise the knowledge sharing.

The hierarchical nature of the concept map allows organizing concepts from the high abstract level to more specific layers. This property can be used by students for managing and structuring data. Following the qualitative analysis techniques, students create their own relations for the concepts which later form their personal concept maps. Students can also be provided with a map structure predefined by teachers. Moving through the study program, they can learn to understand these concepts and recognize the valuable examples of their work in the learning process. During this work, students can provide definitions for the concepts by describing them from their own viewpoints.

Many different approaches that students apply when representing the similar sets of concepts were disclosed. Based on a review of the students' maps, the following commonly occurring situations have been identified:

(i) students often insert superfluous nodes between related concepts;

(ii) the same nodes of the map hierarchy are often moved to different positions in a hierarchical tree;

(iii) one and the same node is frequently represented by one student as the major concept while another considers it as the subsidiary concept;

(iv) a particular node in one map may match many nodes in the other one in the maps built by different students;

(v) students commonly provide different links between the same nodes, hence reflecting different understanding of these relations.

It was found as well that concept mapping without training is very problematic for students that are usually unable to structure and to integrate the information in a proper way. Following $[6,36]$, to produce a favourable outcome we consider that training is a key factor. Because concept maps can be easily explained to learners, we arranged training and map construction at the same time. The students were not asking to generate maps on the computer. During the training they prepared the small hand-written maps suitable for easy reading. We agree with [37] that concept mapping can be introduced to the classroom with relative ease. From 5 to 15 minutes of the concept map training easily fit into nearly any schedule. Consequently, we ranged the time to grade maps from 3 to 10 minutes, which appeared not more timeconsuming than multiple-choice quizzes or short essays.

As a result, our experience has shown how the concept mapping improves students' understanding, what they have acquired from the class, and how they make connections between the class and prior concepts. Mapping reinforces knowledge integration providing the learners with an activity which promotes such integration. As far as students enhance their understanding, they potentially find more suitable evidence in their knowledge area. Because of this dynamic nature of learning, the individual concept map might never be complete [34]. Concept mapping promotes also many discussions, particularly if they are placed onto the screen and students see them. Finally, the maps help to find where and when the students need additional instruction.

\section{Concept Maps as an Assessment Tool}

A further strength of concept maps is their important role in assessment [38]. Concept maps are a valuable tool of assessment procedures because they evidently represent learners' knowledge through multiple feedbacks tailored to students' personal characteristics and requests.

It is difficult to assess what every student knows in a broad subject area. An important feature of concept maps is that they tend to be unique for each student. It is well known that human minds are highly different, especially, when it comes to interpretations such as quality or completeness. It has been reported in [39] that different people would construct different concept maps, even if they answer the same question and share the same level of expertise. Such uniqueness prevents an instructor from doing a quick evaluation since the estimated object is not right or wrong, but rather more complex, elaborate, and precise in direct relation to the students' understanding of the addressed domain. Therefore, the assessment process is prone to be complex and time-consuming and, in general, includes a strong degree of subjectivism, which should be mitigated [40]. The subjectivity appears when the teachers ask the concept maps they constructed for the same knowledge expressed in their lecture or textbooks.

To meet the challenge, it was found in [6] how to assess student's possibility in extracting quantitative and qualitative information about the studied material. In [39] partitioning of the assessment process has been proposed using the steps followed for their creating as well as objective metrics that assign every step. Some authors scored the maps along several dimensions, including their comprehensiveness, the number of details, and the complexity of the links.

We have found that the concept maps as an assessment tool require consideration of at least two issues:

(i) how the maps are designed,

(ii) how they are interpreted.

Effectiveness of these two issues has resulted in two approaches each accomplished by comparing the learner's maps with the expert's ones $[22,38]$. At the former, studentgenerated concepts approach, the maps collect the concepts and links a student identifies relatively to an evaluated domain. The student constructs his map either directly or indirectly, with the help of an instructor who implements the learner's idea. The strength of this method is that emphasis is 

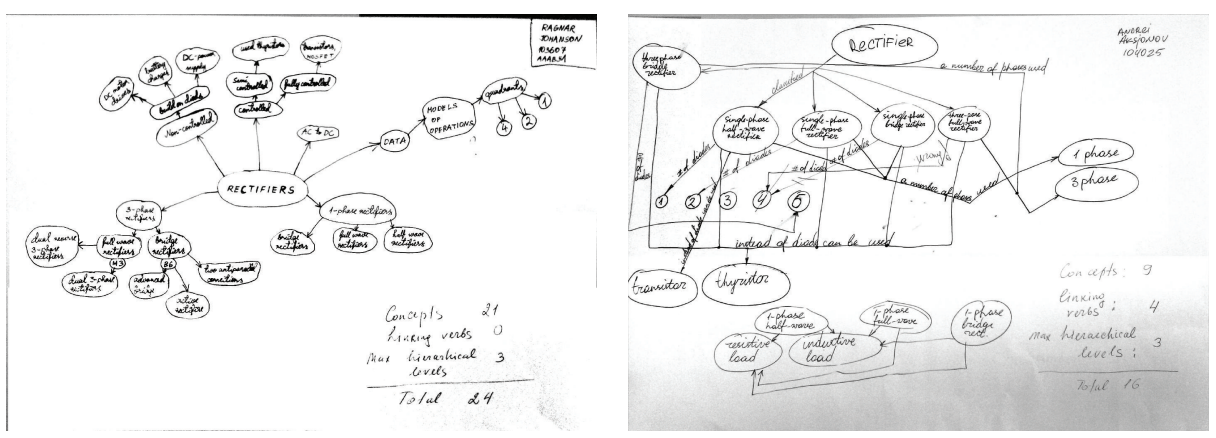

FIGURE 2: Students' concept maps.

done on the understanding of how a particular student appreciates a particular domain. Individual differences of student's understanding can be captured here. However, as the concept maps resulting from this method can be large, complicated, and difficult to interpret, it is usually problematic to provide a final judgment about a student's knowledge. In the second method, called an externally generated concepts approach, the assessment represents a quantitative comparison between two concept maps-the student's and the teacher's map. Following this result, a map is interpreted by determining similarity between these two maps. The referent map might be constructed by a tutor based on his/her own knowledge or a map constructed to represent key knowledge in a textbook. The measure of similarity between the two maps displays the level of the student's knowledge.

The maps submitted by the students are usually quite diverse [22]. A couple of such examples from our practice are shown in Figure 2. Three groups (about 60) second-course bachelor students were asked to build the concept map of the rectifiers studied in a series of lectures, exercises, and labs. The focus problem of mapping was to demonstrate the learners' ability to systematize their knowledge obtained from different sources, such as class lessons, textbooks and tutorials, Internet, and peer-to-peer communications. The examples show that the learners demonstrate different understanding of the concept relations, ranking, linking, and nodding. Some of learners resemble the maps that have been created during the classroom work. Such maps generally receive rather low scores on the comprehensiveness, detailing level, and complexity dimensions. To receive higher grade, the map should represent a large number of concepts, their crosslinks, and hierarchy layers thus showing that the student can differentiate the elements of the domain. The volume of meaningful links contributes to the score significantly.

The map interpretation usually covers both the quantitative scoring and the qualitative judgments on the appropriateness of the assessed model. In our assessment procedure the final grade involves scoring the student's maps along such dimensions: the number of concepts, the number of links, the number of hierarchy levels, and the number of examples. These scoring data stem from the concept mapping goals representing such features as breadth, depth, and connectivity. In addition to the scoring along these dimensions, the maps are commonly inspected for the number of invalid positions as well as the absence of major concepts and relations. During the assessment, every dimension is scored on a scale from zero to five.

The distribution of scores obtained in our experimentations argues that most of the students can reach rather high ratings. This suggests that, by the end of the course, most of the students have acquired the concepts that they learned. For the volume of the acquired details, most of students have received the middle-level scores. This proves differences in the students' possibility to realise detailed concept description. The scoring distribution for concept connectivity has the greatest variation thus showing the difference between the students who learned carefully and those who were less successful in systematic learning.

Of course, the concept maps cannot be the only assessment instrument because they represent a part of the full assessment process. Usually they require much time to interpret and can still remain ambiguous. They do not guarantee that the students are able to apply the concepts in design or other authentic engineering activities.

\section{Conclusion}

It is shown that both the educators and the students have difficulty in development and interpreting the concept maps in Electronics as well as in establishing relationships between the concepts and entities. Being rather complex and timeconsuming task, concept mapping requires considerable efforts in determination of the major concepts and relations. The proposed study opens the useful ways for both the educators and the students in concept mapping application. The recommendations presented how to get better results in Electronics comprehension and assessment. It is shown also that, thanks to its process-oriented nature, concept mapping enlarges opportunities of success in all learning processes.

\section{Conflict of Interests}

The authors declare that there is no conflict of interests regarding the publication of this paper. 


\section{References}

[1] N.-S. Chen, C.-W. Wei, and H.-J. Chen, "Mining e-Learning domain concept map from academic articles," in Proceedings of the 6th International Conference on Advanced Learning Technologies (ICALT '06), pp. 694-698, Kerkrade, The Netherlands, July 2006.

[2] Z. Raud, Research and development of an active learning technology for University-Level education in the field of electronics and power electronics [Doctoral thesis], Tallinn University of Technology, Tallinn, Estonia, 2012.

[3] G. Tokdemir and N. E. Cagiltau, "A concept map approach for introduction to computer engineering course curriculum," in Proceedings of the IEEE Education Engineering Conference (EDUCON '10), pp. 243-250, Madrid, Spain, 2010.

[4] Y.-T. Wu, Y.-M. Ku, Y.-H. Chen, J.-F. Wu, T.-W. Chan, and J.H. Wang, "Curriculum container system: a system to support curriculum and learning activity management," in Proceedings of the 5th IEEE International Conference on Advanced Learning Technologies (ICALT '05), pp. 287-289, Kaohsiung, Taiwan, July 2005.

[5] Y. Wu, "A pilot study of applying hierarchical curriculum structure graph for remedial learning," in Proceedings of the 7th IEEE International Conference on Advanced Learning Technologies (ICALT '07), pp. 103-107, Niigata, Japan, July 2007.

[6] D. Roy, "Using concept maps for information conceptualization and schematization in technical reading and writing courses: a case study for computer science majors in Japan," in Proceedings of the IEEE International on Professional Communication Conference (IPCC '08), pp. 1-12, Montreal, Canada, July 2008.

[7] R. Kavitha, A. Vijaya, and D. Saraswathi, "An augmented prerequisite concept relation map design to improve adaptivity in e-learning," in Proceedings of the International Conference on Pattern Recognition, Informatics and Medical Engineering (PRIME '12), pp. 8-13, Salem, India, March 2012.

[8] J. C. Shieh and Y. T. Yang, "Concept maps construction based on student-problem chart," in Proceedings of the IIAI 3rd International Conference on Advanced Applied Informatics (IIAIAAI '14), pp. 324-327, Kokura Kita-ku, Japan, August-September 2014.

[9] R. Rudraraju, L. Najim, V. P. Gurupur, and M. M. Tanik, "A learning environment based on knowledge storage and retrieval using concept maps," in Proceedings of the IEEE SoutheastCon 2014, pp. 1-6, Lexington, Ky, USA, March 2014.

[10] E. F. Guastello, T. M. Beasley, and R. C. Sinatra, "Concept mapping effects on science content comprehension of lowachieving inner-city seventh graders," Remedial and Special Education, vol. 21, no. 6, pp. 356-364, 2000.

[11] G. P. Jain, V. P. Gurupur, J. L. Schroeder, and E. D. Faulkenberry, "Artificial intelligence-based student learning evaluation: a concept map-based approach for analyzing a student's understanding of a topic," IEEE Transactions on Learning Technologies, vol. 7, no. 3, pp. 267-279, 2014.

[12] G. Thanasis, E. Kehris, H. Samara, and S. Mpakavos, "A framework for supporting creative thinking in concept mapping," in Proceedings of the 14th IEEE International Conference on Advanced Learning Technologies (ICALT '14), pp. 493-494, Athens, Greece, July 2014.

[13] T. R. Gruber, "A translation approach to portable ontology specifications," Knowledge Acquisition, vol. 5, no. 2, pp. 199-220, 1993.
[14] B. Chandrasekaran, J. R. Josephson, and V. R. Benjamins, "What aro ontologies, and why do we need them?" IEEE Intelligent Systems and Their Applications, vol. 14, no. 1, pp. 20-26, 1999.

[15] J. Satzinger, R. Jackson, and S. Burd, System Analysis and Design in a Changing World, Thomson Learning, Cambridge, Mass, USA, 2000.

[16] J. D. Novak and D. B. Gowin, Learning How to Learn, Cambridge University Press, Cambridge, UK, 1984.

[17] J. D. Novak and A. J. Canas, "The theory underlying concept maps and how to construct and use them," Technical Report IHMC CmapTools 2006-01, Rev 01-2008, Florida Institute for Human and Machine Cognition, 2008, http://cmap.ihmc.us/ Publications/ResearchPapers/TheoryUnderlyingConceptMaps .pdf.

[18] D. P. Ausebel, The Psychology of Meaningful Verbal Learning, Grune and Stratton, New York, NY, USA, 1963.

[19] Z. Raud, V. Vodovozov, and T. Lehtla, "Flexible curricula for elearning of SME staff in electronic engineering," in Proceedings of the 9th IEEE/ACIS International Conference on Computer and Information Science (ICIS '10), pp. 384-388, Yamagata, Japan, August 2010.

[20] Z. Raud and V. Vodovozov, "Staff training for servicing special power electronic applications," in Proceedings of the 7th International Conference-Workshop Compatibility and Power Electronics (CPE '11), pp. 319-324, Tallinn, Estonia, June 2011.

[21] Z. Raud, V. Vodovozov, and T. Lehtla, "Enhancing students' activity in electrical engineering through Web and social networks," in Proceedings of the 3rd IEEE Global Engineering Education Conference (EDUCON '12), Marrakesh, Morocco, April 2012.

[22] J. Turns, C. J. Atman, and R. Adams, "Concept maps for engineering education: a cognitively motivated tool supporting varied assessment functions," IEEE Transactions on Education, vol. 43, no. 2, pp. 164-173, 2000.

[23] J. March and O. Martinez, "Using cognitive informatics to learn cooperatively databases through the web," IEEE Multidisciplinary Engineering Education Magazine, vol. 2, no. 4, pp. 7-11, 2007.

[24] R. Morsi, W. Ibrahim, and F. Williams, "Concept maps: development and validation of engineering curricula," in 37th Annual Frontiers in Education Conference-Global Engineering: Knowledge Without Borders, Opportunities Without Passports (FIE '07), pp. T3H-18-T3H-23, Anaheim, Calif, USA, October 2007.

[25] H. Funaoi, E. Yamaguchi, and S. Inagaki, "Collaborative concept mapping software to reconstruct learning processes," in Proceedings of the International Conference on Computers in Education (ICCE '02), vol. 1, pp. 306-310, Los Alamitos, Calif, USA, December 2002.

[26] E. J. Lorenzo, M. Rodriguez-Artacho, and B. B. Blanco, "Using collaborative concept maps for coordination and knowledgesharing in learning communities for science," in Proceedings of the 11th IEEE International Conference on Advanced Learning Technologies (ICALT '11), pp. 558-562, Athens, Ga, USA, July 2011.

[27] E. Barkley, K. Cross, C. Major, E. F. Barkley, K. P. Cross, and C. H. Major, Collaborative Learning Techniques: A Handbook for College Faculty, Jossey-Bass, New York, NY, USA, 2005.

[28] E. Prasolova-Forland and M. Divitini, "Supporting learning communities with collaborative virtual environments: different spatial metaphors," in Proceedings of the 2nd IEEE International 
Conference on Advanced Learning Technologies (ICALT '02), pp. 58-67, Kazan, Russia, 2002.

[29] Z. Raud and V. Vodovozov, "Curricula scheduling using educational thesaurus," in Proceedings of the World Congress on Computer Science and Information Technology (WCSIT '11), Cairo, Egypt, 2011, paper 092.

[30] Z. Raud and V. Vodovozov, "Flexible curricula based on educational thesaurus," in Proceedings of the 15th IASTED International Conference on Computers and Advanced Technology in Education (CATE '12), pp. 219-226, Napoli, Italy, 2012.

[31] Z. Raud, V. Vodovozov, and T. Lehtla, "Educational thesaurus for learning electronics," in Proceedings of the 3rd World Conference on Education and Educational Technologies (WORLD-EDU '12), pp. 67-72, Athens, Greece, 2012.

[32] Z. Raud and V. Vodovozov, "Educational thesaurus of power electronics," in IEEE International Conference on Computer as a Tool (EUROCON '11), pp. 1-4, Lisbon, Portugal, 2011, paper 249.

[33] J. J. Villalon and R. A. Calvo, "Concept map mining: a definition and a framework for its evaluation," in Proceedings of the IEEE/WIC/ACM International Conference on Web Intelligence and Intelligent Agent Technology-Workshops (WI-IAT '08), pp. 357-360, Sydney, Australia, December 2008.

[34] Y. Bozhko and E. Heinrich, "Concept map-based framework for learner-centered knowledge management in ePortfolios," in Proceedings of the 11th International Conference on Advanced Learning Technologies (ICALT '11), pp. 160-162, IEEE, Athens, Ga, USA, July 2011.

[35] C.-K. Chang and C.-H. Tsai, "Behavioral analysis of using concept maps for ESL reading comprehension on mobile learning devices," in Proceedings of the 4th International Conference on Machine Learning and Cybernetics (ICMLC '05), pp. 5548-5553, Guangzhou, China, August 2005.

[36] B. Marshall and T. Madhusudan, "Element matching in concept maps," in Proceedings of the Joint ACM/IEEE Conference on Digital Libraries (JCDL '04), pp. 186-187, Tucson, Ariz, USA, June 2004.

[37] R. Peters, "Concept mapping in the automotive technology management classroom: does it lead to higher scores on traditional multiple-choice exams?" in Proceedings of the 35th ASEE/IEEE Frontiers in Education Conference, pp. T2F-26-T2F27, Indianopolis, Ind, USA, 2005.

[38] E. Gouli, A. Gogoulou, K. Papanikolaou, and M. Grigoriadou, "Evaluating learner's knowledge level on concept mapping tasks," in Proceedings of the 5th IEEE International Conference on Advanced Learning Technologies (ICALT '05), pp. 424-428, Washington, DC, USA, July 2005.

[39] C. T. Calafate, J.-C. Cano, and P. Manzoni, "A comprehensive methodology for concept map assessment," in Proceedings of the 9th IEEE International Conference on Advanced Learning Technologies (ICALT '09), pp. 15-17, Riga, Latvia, July 2009.

[40] P. Stockwella, A. E. Smith, and J. Wilesa, "Displaying a framework in a concept map using network graph techniques," in Proceedings of the 13th International Conference on Information Visualisation (IV'09), pp. 661-666, Barcelona, Spain, July 2009. 

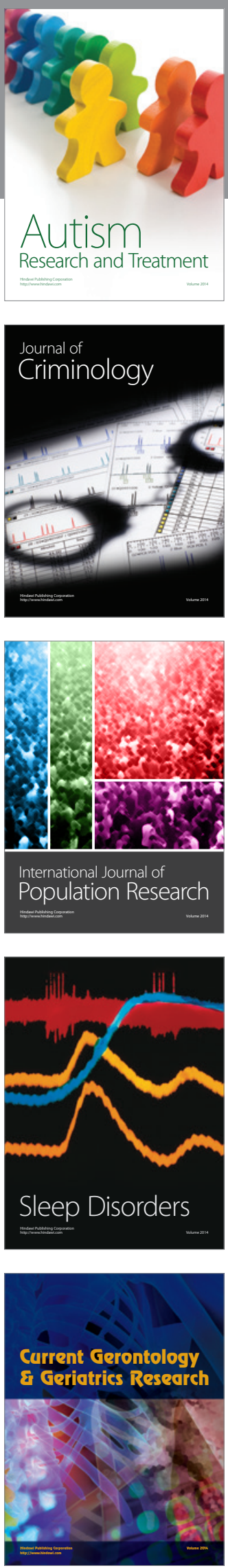
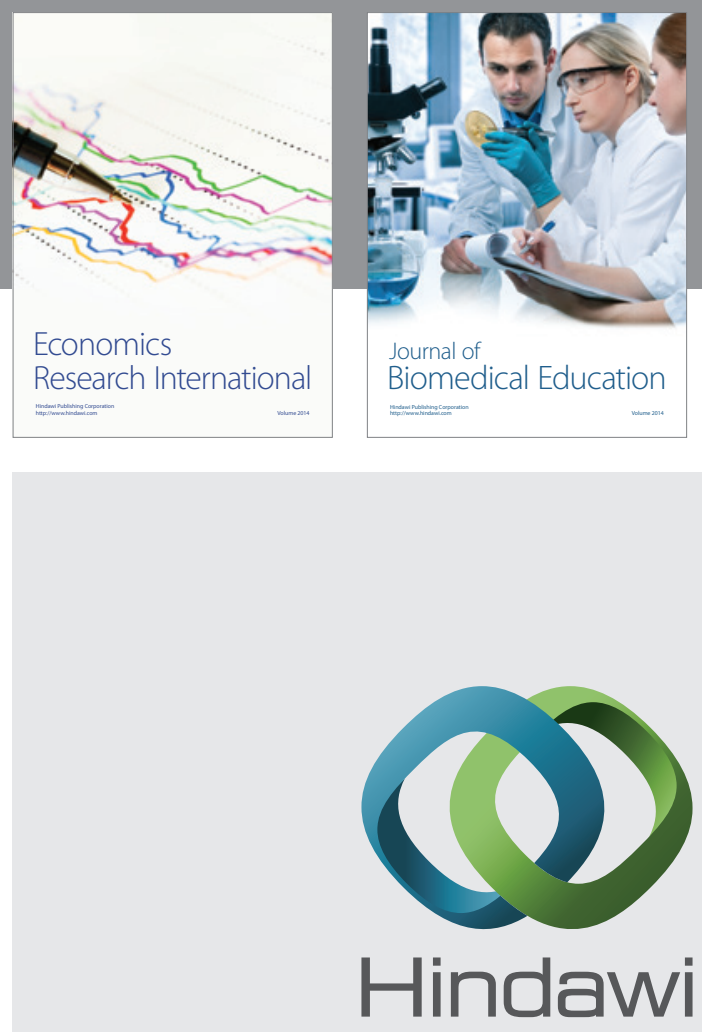

Submit your manuscripts at

http://www.hindawi.com
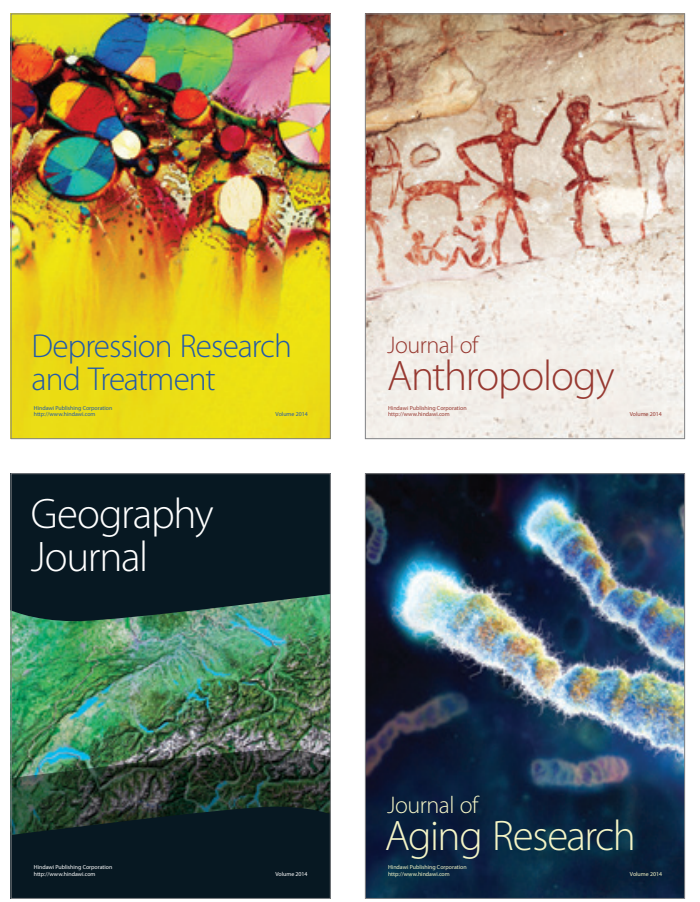
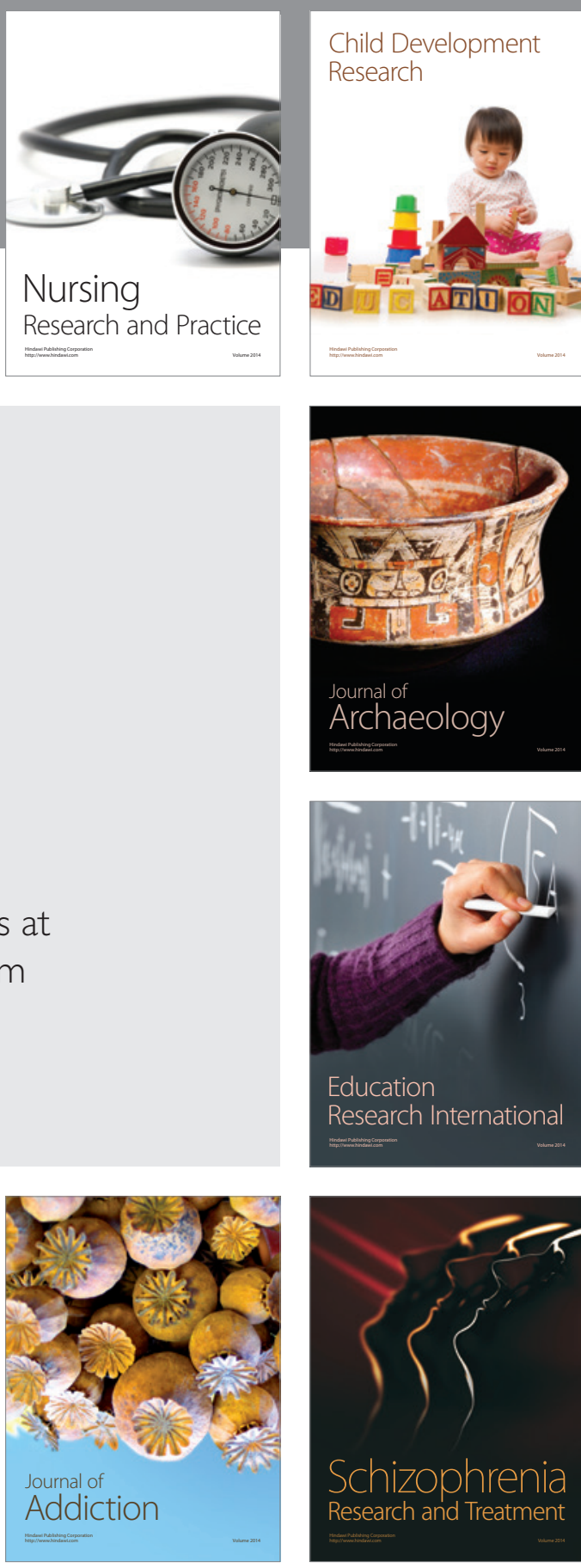

(D)
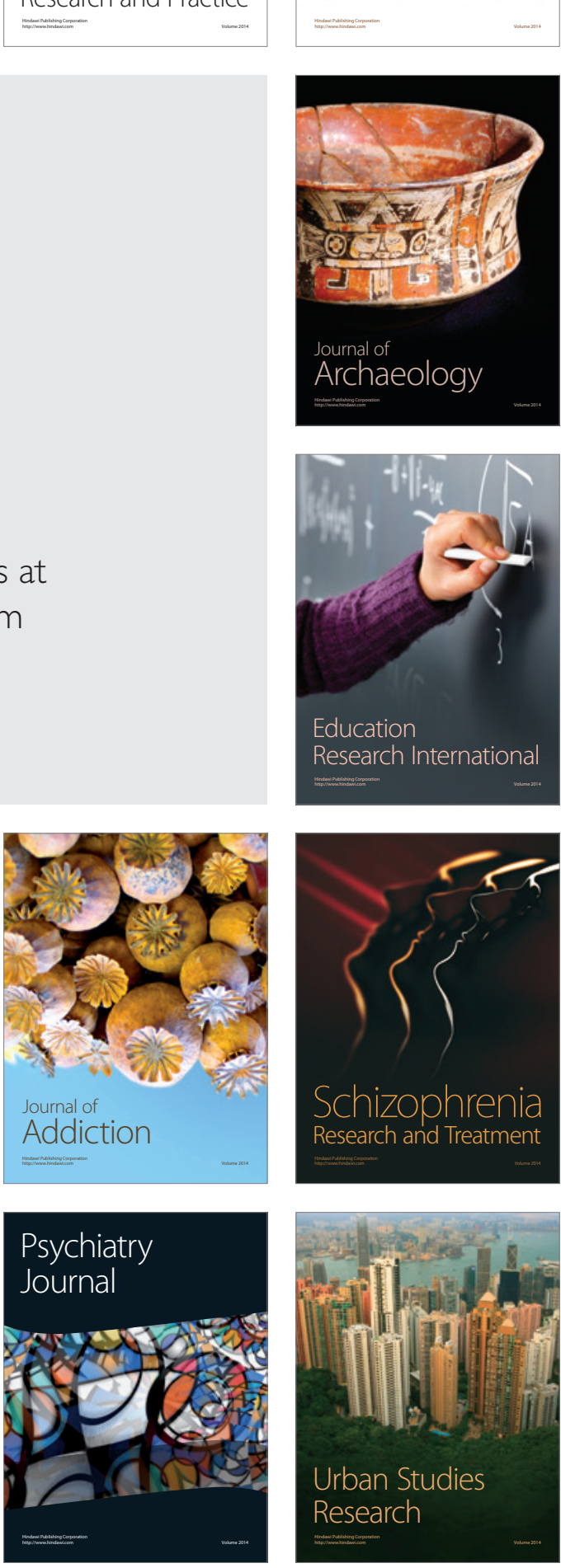